\title{
First report of Neopestalotiopsis clavispora causing postharvest fruit rot of loquat in Pakistan
}

\author{
Muhammad Fahim Abbas ${ }^{1}$ (D) $\cdot$ Sana Batool ${ }^{2} \cdot$ Tamoor Khan $^{3} \cdot$ Muhammad Rashid $^{3}$
}

Received: 5 February 2021 / Accepted: 2 November 2021 / Published online: 9 January 2022

(c) Società Italiana di Patologia Vegetale (S.I.Pa.V.) 2021

Keywords Morpho-molecular characterization $\cdot$ Nucleotide evidence $\cdot$ Evolutionary history

Loquat [Eriobotrya japonica (Thunb.) Lindl.] has largest cultivated areas in Pakistan. During 2014-2016, brownish spots were recorded at stilar end of the fruits with 35 to $40 \%$ disease incidence. Sodium hypochlorite (1\%) was used for surface disinfection and fruits were shifted on PDA at $25{ }^{\circ} \mathrm{C}$ with a 12 -h photoperiod. The white cottony fungal colonies with undulate edge, pale luteous at reverse side and circular (upper side) were recorded after 7 days. The black and concentric acervuli (avg. $269 \mu \mathrm{m})$ were recorded after 9 days. Five cell conidia (average $21.6 \times 7.5 \mu \mathrm{m})(\mathrm{n}=50)$ were fusiform to ellipsoid with dark brown (third and fourth) and pale brown (second) cells. Two to four apical appendages (avg. $24.8 \mu \mathrm{m}$ ) and one basal appendage (average $9.3 \mu \mathrm{m}$ ) were recorded in the conidia. The morphological characterizations indicated Neopestalotiopsis clavispora (G.F. Atk.) Steyaert (Maharachchikumbura et al. 2014). The mycelial plugs $(5 \mathrm{~mm})$ from fungal culture of FHM isolate were shifted on disinfected wounded and non-wounded loquat fruit cv. Surkh. The media

Muhammad Fahim Abbas

fahim.abbas@luawms.edu.pk

Sana Batool

sanabatool2014@gmail.com

Tamoor Khan

qumberani1@yahoo.com

Muhammad Rashid

rashedlatif@yahoo.com

1 Department of Plant Pathology, Faculty of Agriculture, Lasbela University of Agriculture, Water \& Marine Sciences (LUAWMS), Uthal, Balochistan, Pakistan

2 College of Plant Protection, Northwest Agriculture and Forestry University, Xianyang, China

3 Faculty of Agriculture, Lasbela University of Agriculture, Water \& Marine Sciences (LUAWMS), Uthal, Balochistan, Pakistan plugs were used as a negative control and experiment was conducted twice. The lesions were recorded on inoculated fruits after 10 days at $25^{\circ} \mathrm{C}$, while no lesions were recorded on negative control. The fungus was re-isolated from these lesions and morphological characterization was similar with mother culture (FHM isolate). The molecular characterization was performed by sequencing of D1/D2 region with NL1/NL4 primers in the $5^{\prime}$ end of the $28 \mathrm{~S}$ rDNA gene (GenBank accession No. MW480225) and rDNA ITS15.8S-ITS2 region (MW471686) with ITS1/ITS4 primers. The sequences were exhibiting $99 \%$ genetic similarity with previously reported N. clavispora isolates (Palou et al. 2013). This fungus has caused post-harvest fruit rot of loquat in Spain (Palou et al. 2013) but to our knowledge, this is first report of $N$. clavispora on loquat in Pakistan.

\section{Declarations}

Conflict of interest Authors have no conflict of interest.

\section{References}

Maharachchikumbura SS, Hyde KD, Groenewald JZ, Xu J, Crous PW (2014) Pestalotiopsis revisited. Stud Mycol 79:121-186

Palou L, Montesinos-Herrero C, Guardado A, Taberner V (2013) First report of Pestalotiopsis clavispora causing postharvest fruit rot of loquat in Spain. J Plant Pathol 95(S4):69

Publisher's Note Springer Nature remains neutral with regard to jurisdictional claims in published maps and institutional affiliations. 